\title{
Being a Beast
}

\section{Erhard Taverna}

Dr. med., Mitglied der Redaktion

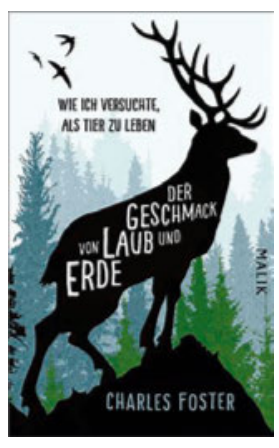

Charles Foster

\section{Der Geschmack von Laub und Erde}

Originaltitel: Being a Beast

Aus dem Englischen von Gerlinde Schermer-Rauwolf und Robert A. Weiß

München/Berlin: Piper Verlag; 2. Auflage 2017

288 Seiten. $29.90 \mathrm{CHF}$

ISBN 978-3-89029-262-5

Aus dem Titel «Ein Tier sein» wurde in der deutschen Buchausgabe, weniger prägnant, «Der Geschmack von Laub und Erde.» Der Autor Charles Foster eröffnet seinen Bericht mit dem Satz: «Ich wollte wissen, wie es ist, ein Wildtier zu sein.» Der Tierarzt, Anwalt und Familienvater unterrichtet Ethik und Rechtsmedizin in Oxford. Er hat sich jahrelang darauf vorbereitet, Artengrenzen zu überwinden, bevor er versuchte, als Dachs, Otter, Fuchs, Hirsch und Mauersegler zu leben. Das klingt ziemlich verrückt, und dennoch ist daraus ein sehr schönes und eindrückliches Sachbuch geworden.

Geholfen haben ihm dabei die Neurowissenschaften, viel Physiologie, viel Landschaftskunde, etwas Philosophie und eine Menge Lyrik. Ein literarischer Schamanismus, der ihm sagenhaft Spass gemacht habe. Auch wenn, oder besser, weil er viele Unannehmlichkeiten auf sich nahm, in einer Erdhöhle lebte, Würmer verspeiste, wie ein Penner in Londons Hinterhöfen lebte oder auf einen Baum stieg, um nach Mücken zu schnappen. Unverzichtbar waren sein immenses Wissen, seine exzentrische Neugier, physische Ausdauer und eine erfrischende Portion Humor und Selbstironie. Auf einer Lesereise gefragt, ob es ihm ebenso sehr ums Menschsein wie ums Tiersein gegangen sei, meinte er, es sei ein unheilbar anthropomorphes Buch herausgekommen. Intellektuell, reduktionistisch und sprachorientiert, sei er geneigt, die Welt in Aussagen zu zerlegen. Um diese Schranken zu überwinden, hat er eine Methode sinnlicher Versenkung trainiert, in dem er etwa verschiedene Käsesorten in seinem Arbeitszimmer faulen liess, um sich ausschliesslich nach dem Geruch $\mathrm{zu}$ orientieren. Viele Jahre lang war Foster ein leidenschaftlicher Jäger, was er heute bereue. Seine Seele sei dadurch abgestumpft und schwielig geworden. Doch geschärft hat das Töten seine Sinne, das Riechen, Beschnuppern, Kriechen und Belauern, das Ertragen von
Bremsen und Blutegeln, von Kälte und Dunkelheit - Eigenschaften, die ihm bei seinem Selbstversuch zu Gute kamen. Oder mit typischem Fosterschem Humor: «Neoprenanzüge sind Kondome, die verhüten, dass unsere Fantasie durch Bergflüsse befruchtet wird.» Sein Fazit: man muss es fühlen, um es zu erkennen. Damit es ihm als Mensch gut ging, musste er mehr Dachs werden. Die Otter waren ihm unsympathisch, den Füchsen fühlte er sich am meisten verbunden, Rothirschen kam er emotional nie nahe, obwohl er monatelang seine Zehennägel nicht mehr schnitt, um das Gefühl von Hufen kennen zu lernen. Und beim Mauersegler kam es zu keiner wirklichen Begegnung, obwohl er deren Wanderungen bis in den Kongo folgte. Eine metaphysische Entdeckungsreise ist nicht billig zu haben, sie bedarf enormer Anstrengungen. "Man muss sich in der Erde dreckig machen, in der Luft frieren und Ängste durchstehen, sich vom Feuer versengen lassen und im Wasser seekrank werden. Man muss mit den gleichen Pfotenbewegungen oder Flügelschlägen unermüdlich an der Welt kratzen wie die Tiere, die man kennenlernen möchte.» Natürlich kennt Foster alle Einwände, die gegen sein Experiment sprechen. Er weiss um die ungeklärte Frage von der Herkunft menschlichen oder tierischen Bewusstseins und hat doch einige animalische Andere kennengelernt. «Die Wälder sind voll von schleichenden Dus.» Auf die Frage, ob Tiere in derselben Welt lebten wie wir, habe er bis zum Schluss keine Antwort gefunden und sei letztendlich froh darüber. Denn das Wissen um diese nichtmenschlichen Existenzen tröstet ihn, wenn er sich an Orte begibt, die nach Angst, Abgasen und Ehrgeiz stinken. Trotzdem bleibt Foster am Ende seiner Expeditionen ins Tierreich äusserst selbstkritisch: «Ich stelle fest, dass ich ein ähnlich tröstliches Gefühl nur dann empfinde, wenn ich mich der fortdauernden Existenz von etwas - insbesondere von Menschen - versichern kann, das beziehungsweise die ich liebe (was immer Liebe sein mag). Was notwendigerweise auf Gegenseitigkeit beruht.»

Der Feldversuch hat vieles verändert. Die Erfahrung habe ihn zu einer Art biologischem und politischem Kommunitarismus bekehrt. Und mit britischem Understatement: «Das Insistieren auf der völligen Autonomie des Menschen hat einige ziemlich seltsame Ergebnisse gezeitigt.» 